\title{
Maternal HIV Seropositivity and Perinata//Neonatal Outcome at Ebonyi State University Teaching Hospital, Abakaliki, Nigeria
}

\author{
Julie U. Ojukwu' and Perpetus C. Ibekwe ${ }^{2}$ \\ Departments of ${ }^{1}$ Paediatrics and ${ }^{2}$ Obstetrics \& Gynaecology, Ebonyi State University Teaching Hospital, Abakaliki, \\ Ebonyi State, Nigeria.
}

\begin{abstract}
Context: HIV seropositivity in pregnancy has been an issue of major concern worldwide. This is because of the risk of mother to child transmission which is associated with adverse perinatal/neonatal outcome.

Objective: To determine the maternal HIV seropositivity and perinatal/neonatal outcome.

Study Design, Setting and Subjects: A retrospective audit of all cases of HIV seropositivity among the antenatal mothers seen at the Ebonyi State University Teaching Hospital, Abakaliki, over a three-year period (January 2001December 2003) as well as the outcome of their babies was carried out.

Results: Out of 9,865 women who registered for antenatal care during the study period, $1,704(17.3 \%)$ were screened for HIV infection. Of these, 91 (5.3\%) were confirmed positive. Twenty-four mothers $(26.4 \%)$ absconded after diagnosis and 67 case files $(73.6 \%)$ were available for analysis. The highest seropositive rate occurred in the age group $26-30$ years constituting $41.8 \%$ (28/67) while primigravidae alone accounted for $28.4 \%(19 / 67)$. Most of the mothers were housewives $(31.3 \%, 21 / 67)$ while their husbands were mainly farmers $(37.4 \%, 25 / 67)$ and transporters $(28.4 \%$, 19/67). Fifteen mothers $(22.4 \%)$ showed features suggestive of AIDS. Of the 66 babies, $49(74.2 \%)$ were term, 17 $(25.8 \%)$ were preterm while $56(84.8 \%)$ were of low birth weight $(<2500 \mathrm{~g}), 24(36.4 \%)$ were admitted for presumed sepsis while 4 had proven sepsis. None had fetal abnormality. There were 15 deaths giving a mortality of $22.7 \%$ (Perinatal death of $12 / 66(18.2 \%)$ and neonatal death of $3 / 66(4.5 \%)$.

Conclusion: High HIV seropositive prevalence rate, high rate of loss to follow up (abscondment), high positive rate in young mothers with adverse perinatal/neonatal outcome call for cost effective measures to be put in place to take care of HIV positive mothers and their babies as these were evidently lacking in the study area.
\end{abstract}

Key Words: Maternal HIV Seropositivity, Perinatal, Neonatal, Outcome. [Trop J Obstet Gynaecol, 2005, 22: 33-36]

\section{Introduction}

African women of childbearing age are particularly vulnerable to HIV infection. This has led to an increase in the number of paediatric HIV infections reported due to the risk of mother-to-child transmission (MTCT) of HIV during pregnancy, delivery and breastfeeding '. About three-quarters of infections occur around the time of delivery in non-breastfeeding populations and in the absence of specific interventions, the vertical transmission rate is up to $30 \%$ or more in some countries ${ }^{2}$. All children born to HIV positive women test HIV positive themselves at birth and for 12-18 months thereafter because of passive transfer of antibodies from mother to child ${ }^{1,2}$. High maternal load is the major risk factor for both intra-uterine and intra-partum mother-tochild transmission, and HIV infection in pregnant women has been shown to have an adverse effect on not only the mother but also the fetus ${ }^{3}$. Prematurity is the most common adverse neonatal outcome associated with maternal HIV infection, followed by low birth weight, intra uterine growth retardation, spontaneous abortion, fetal abnormality, neonatal sepsis, increased neonatal/perinatal/ infant mortality rates ${ }^{2.3}$.

In the 1999 National HIV Sero-Prevalence Survey, Ebonyi State recorded a sero-prevalence rate of $11.1 \%$ among antenatal care (ANC) attendees, thereby making the state one of the hot spot states in the south east health zone in Nigeria ${ }^{4}$. HIV infection has therefore become a real issue in Ebonyi State since this survey. In 2000, a routine HIV screening in pregnant women was adopted in the study hospital. Despite this, many either abscond when they are found to be HIV positive or fail entirely to present themselves for the test. There has not been any previous report from Ebonyi State University Teaching Hospital, Abakaliki to the best of our knowledge on the maternal HIV seropositivity and possible adverse effect on the mother and the fetus. We report here the maternal HIV seropositivity and perinatal/neonatal outcome as seen at the Ebonyi State University Teaching Hospital (EBSUTH) Abakaliki, Nigeria.

\section{Subjects and Methods}

A three-year retrospective analysis of antenatal care records of pregnant women attending Ebonyi State University Teaching Hospital, Abakaliki between January 1, 2001 and December 31, 2003 was carried

Correspondence: Dr (Mrs) J.U. Ojukwu, P.M.B 077, Abakaliki,Ebonyi State.E-mail:julieojk@yahoo.com 
out. This hospital is a major referral center serving the whole of Ebonyi State and some parts of Cross River State with an estimated population of over 2 million people. The hospital was a sentinel site for the 1999 , 2001 and 2003 national HIV sero-prevalence survey on antenatal clinic attendees. The majority of the inhabitants are peasant farmers quite often polygamous in order to help out with farm work and a home to a thriving national/international rice industry/market. The area is replete with long distance drivers and commercial sex workers both on temporary and permanent basis.

The following maternal data were extracted: age, parity, previous abortions and sibling deaths, past history of blood transfusion, occupation of mothers and fathers, symptoms and signs of 'HIV infection and outcome. Neonatal data also obtained, included gender, birthweight, gestational age at delivery, mode of delivery, physical features, associated conditions for sepsis, perinatal and neonatal outcome. The extracted data extended up to six weeks postpartum.

The mothers were screened for the HIV-antibody status for HIV 1 and HIV 2 using the ELISA test kits (ACON HIV 1 \& 2) at their initial booking visits following pretest counseling. If tested negative, the mother was labeled as HIV negative, and if tested positive then it was confirmed by a second ELISA using a different kit (Uni-Gold ${ }^{\mathrm{TM}} \mathrm{HIV}$ ). If tested positive, then a confirmatory Western Blot (WB) was done at the University of Nigeria Teaching Hospital, (UNTH) Enugu. If WB was positive then the mother was labeled as HIV positive. Where the mother was unable to carry out WB due to various reasons, at delivery the two positive ELISA was considered in this study as positive as recommended by World Health Organization (WHO). At birth, the babies of HIV positive mothers were screened using the ELISA test kits. If tested negative, the baby was labeled as HIV negative, and if tested positive the babies were referred to UNTH, Enugu for WB test. Where the WB test was not available in the records, the baby was considered an indeterminate infant.

Table 1

Age Distribution of HIV Sero-Positive Mothers

\begin{tabular}{ccc}
\hline Age (years) & $\begin{array}{c}\text { Number } \\
\text { of Patients }\end{array}$ & $\begin{array}{c}\text { Percentage } \\
\text { of Total }\end{array}$ \\
\hline $16-20$ & 9 & 13.4 \\
$21-25$ & 17 & 25.4 \\
$26-30$ & 28 & 41.8 \\
$31-35$ & 10 & 14.9 \\
$>35$ & 3 & 4.5 \\
Total & 67 & 100.0 \\
\hline
\end{tabular}

\section{Results}

A total of 9,865 women were booked for antenatal care during the period under review. One thousand seven hundred and four $(17.3 \%)$ of these underwent HIV screening out of whom 91 (5.3\%) were confirmed seropositive. Twenty-four (26.4\%) of the 91 cases absconded soon after the diagnosis. Sixty-seven $(73.6 \%)$ case notes were available for review. Four $(6.0 \%)$ mothers had received blood transfusion in the past while $63(94.0 \%)$ mothers did not. Four mothers and their 4 babies were confirmed positive by Western Blot and they had anti retroviral therapy during pregnancy and post partum period and babies had positive ELISA tests. The rest were confirmed by 2 positive ELISA tests. Forty-eight $(71.6 \%)$ babies were delivered via spontaneous vertex, $15(22.4 \%)$ babies via emergency cesarean section for other causes and 4 $(6.0 \%)$ via elective cesarean. Six $(8.9 \%)$ of the 67 cases had spontaneous abortion, $1(1.5 \%)$ had termination of pregnancy. The remaining 60 mothers delivered at EBSUTH. There were 66 babies (there were 6 sets of twins), all had ELISA done at delivery and they were all positive.

\section{Table 2}

Parity Distribution of HIV Sero-Positive Mothers

\begin{tabular}{ccc}
\hline Parity & $\begin{array}{l}\text { Number } \\
\text { of patients }\end{array}$ & $\begin{array}{l}\text { Percentage } \\
\text { of Total }\end{array}$ \\
\hline 0 & 19 & 28.4 \\
$1-4$ & 44 & 65.7 \\
$\geq 5$ & 4 & 5.9 \\
Total & 67 & 100.0 \\
\hline
\end{tabular}

Age distribution of HIV positive mothers are shown in Table 1. The highest seropositive rate occurred in the age group $26-30$ years, $28 / 67(41.8 \%)$, followed by age group 21-25 years, $17 / 67(25.4 \%)$. The parity distribution of HIV sero-positive mothers is shown in Table 2. Mothers of parity group 1-4 constituted the highest number $44 / 67(65.7 \%)$, followed by primigravidae $19 / 67(28.4 \%)$. The occupational distribution of the mothers and their husbands are shown in Table 3. Most of the mothers 21/67 (31.3\%) were housewives, followed by petty traders $14 / 67$ $(20.9 \%)$ and farmers $12 / 67(17.9 \%)$. Their husbands were mainly farmers $25 / 67(37.4 \%)$, followed by transporters 19/67 (28.4\%) and soldiers/policemen $9 / 67$ $(13.4 \%)$.

Fifteen $(22.4 \%)$ mothers were symptomatic during pregnancy while $52(77.6 \%)$ were asymptomatic. The symptomatic patients had weight loss $15 / 15(100.0 \%)$, skin rashes $15 / 15(100.0 \%)$, recurrent fever $14 / 15$ $(93.3 \%)$, chronic diarrhoea $11 / 15(73.3 \%)$, and pneumonia $8 / 15(53.3 \%)$. Of the 66 babies, there 41 
Table 3

Occupation of HIV Sero-Positive Mothers and their Husbands.

\begin{tabular}{lcccc}
\hline Occupation & $\begin{array}{c}\text { Mothers } \\
\text { No. of Patients }\end{array}$ & $\%$ & $\begin{array}{c}\text { Husbands } \\
\text { No. of Patients }\end{array}$ & $\%$ \\
\hline House wives & $21^{*}$ & 31.3 & - & - \\
Petty traders & $14^{*}$ & 20.9 & 5 & 7.5 \\
Farmers & 12 & 17.9 & $25^{*}$ & 37.3 \\
Civil servants & 9 & 13.4 & 5 & 7.5 \\
Teachers & 6 & 9.0 & 2 & 3.0 \\
Students & 5 & 7.5 & 2 & 3.0 \\
Transporters & - & - & $19 *$ & 28.3 \\
Soldiers/policemen & - & - & 9 & 13.4 \\
Total & 67 & 100.0 & 67 & 100.0 \\
\hline
\end{tabular}

males and 25 females giving a M: F ratio of 1.64:1. Forty-nine (74.2\%) were term babies, 17 (25.8\%) were preterm and 56 babies $(84.8 \%$ ) were of low birth weight $(<2500 \mathrm{~g})$. Twenty-six babies $(39.4 \%)$ were admitted for presumed sepsis and 4 had proven sepsis, 24 babies $(36.4 \%)$ were treated for impetigo neonatorum, 11 babies $(16.7 \%)$ had neonatal jaundice and 8 babies $(12.1 \%)$ had ophthalmia neonatorum. None had fetal abnormality. There were 15 deaths giving a mortality of $22.7 \%$. This included 2 fresh still births, 4 macerated still births, 6 early neonatal deaths and 3 late neonatal deaths (perinatal deaths of $12 / 66$, and neonatal deaths of $3 / 66$,).

\section{Discussion}

Among the 91 HIV sero-positive mothers in the present study, $26.4 \%$ absconded when they became aware of their results. This high default rate following diagnosis raises questions about the adequacy of counseling and the degree of confidentiality inherent in our practice. There is also the issue of stigmatization of patients by health workers and the society at large. Similar observation was also made by Offiong et al ${ }^{5}$ who recorded higher default rate of $55.0 \%$ and Ogu et al ${ }^{6}$ who noted that majority of the HIV sero-positive pregnant women in their series were lost to follow up. This behavior portends grave danger in our environment as no definite intervention or plan was made for those that absconded. Thus information and education are still necessary in order to make mothers in their child-bearing ages realize the need to avail themselves of the measures that reduce the transmission ofHIV infection to their babies.

HIV sero-positive rate in the present study was high $(5.3 \%)$, this is similar to $5.4 \%$ recorded for Nigeria during the 1999 sentinel surveillance ${ }^{4}$ but slightly lower than HIV sero-positivity rates of $8.3 \%, 6.0 \%$ and $6.8 \%$ recorded by Abuja, Kaduna ${ }^{7}$ and Nnewi $^{8}$ studies respectively. Etuk and Ekure from Calabar ${ }^{9}$ recorded a much lower rate of $2.7 \%$. Different seropositivity/transmission rates occur in different cities and countries because of different study and laboratory methods, and different patient case-mix ${ }^{10}$. MTCT is more common in developing countries, where $25-30 \%$ of children of HIV positive mothers becomes HIV infected, compared with $15-20 \%$ in developed world ${ }^{10}$. Our result shows that the seropositivity rate was highest in the age group of $26-30$ years $(41.8 \%)$. This result is similar to the study by Offiong et $\mathrm{l}^{5}$ who found that HIV sero-positivity was most prevalent in the age group 26-30 years $(41.3 \%)$. These women are just commencing their reproductive career and it is well documented that African women of childbearing age are particularly vulnerable to HIV infection, and this has led to an increase in the number of paediatric HIV infections reported due to mother to child transmission ofHIV infection.

Even though majority of the mothers $(77.6 \%)$ were asymptomatic in the present series, quite a reasonable number $(22.4 \%)$ manifested various symptoms of AIDS. This differs from the study by Offiong et al ${ }^{5}$ who recorded a higher rate of $72.4 \%$ in syrnptomatic group while Ogu et al ${ }^{6}$ recorded that only $12.5 \%$ of cases had features of AIDS. The high percentage in this study would call for aggressive antenatal management. History of blood transfusion as a possible route of infection was documented in only $6.0 \%$. Thus, it is assumed that the HIV seropositive mothers may have contracted HIV through unprotected sexual exposure. Offiong et al ${ }^{5}$ documented only $10 \%$ history of past blood transfusion in the mothers.

Most of the mothers $(31.3 \%)$ were housewives and petty traders $(20.9 \%)$ while most of their spouses were farmers $(37.4 \%)$ and transporters $(28.4 \%)$. Our result is similar to the Abuja study ${ }^{5}$ where most of the women were housewives but differed in the occupation of their spouses who were either traders or civil servants $(74.0 \%)$. The reasons for these could be that most of the indigenes are farmers. Again most of the farmers are polygamous, thus exposing themselves to multiple sexual partners and the abundance of commercial sex 
workers who often operate around the long distant bus stops is an added factor. These may be the sources of HIV transmission to the mothers.

Prematurity, low birth weight, intrauterine growth retardation, neonatal sepsis have been shown as common adverse neonatal outcome associated with maternal HIV infection ${ }^{2,3}$. The findings in this study are not different as $25.8 \%$ of the babies were premature, $83.6 \%$ were low birth weight babies, $39.4 \%$ had presumed neonatal sepsis and $36.4 \%$ had impetigo neonatorum. Only six stillbirths were recorded among the babies with over all mortality rate of $22.7 \%$. This is in contrary to another report ${ }^{6}$ where $75.0 \%$ of the babies were still births and $12.5 \%$ suffered neonatal deaths, while Offiong et $a l^{5}$ recorded lower perinatal deaths in $13.6 \%$.

HIV seropositive rate of $100.0 \%$ was noted in the babies in the present study. This is not surprising as all children born to HIV positive women test HIV positive themselves at birth and for 12-18 months thereafter ${ }^{1.2}$. This often represents an over estimation of vertical transmission as most of it may be due to passage of maternal IgG to the fetus. Since only four babies were subjected to Western Blot test by the six weeks postpartum follow up it was difficult to confirm the number of babies who were actually infected. Follow up prospective study up to 18 months of age and beyond will help identify the exact number of babies who are actually infected with the virus in the absence of confirmatory tests. Further study is urgently needed with polymerase chain reaction (PCR) in order to get an accurate vertical transmission rate in the study area as this will sort out babies with passive transfer of antibodies from the mothers as opposed to those who are actually infected with HIV. Regardless, urgent intervention is necessary to reduce the risk of vertical

\section{References}

1. Castetbon K, Leroy V, Spira R, Dabis F. Preventing the transmission of HIV1 from mother to child in Africa in the year 2001. Sante, 2000; 10:103-13.

2. Thorne C, Newell ML. Epidemiology of HIV infection in the newborn. Early Human Development, 2000; 58: :-16.

3. Aiken CG. HIV-1 infection and perinatal mortality in Zimbabwe. Arch Dis Child, 1992; 67: 595-9.

4. National Sero-prevalence Sentinel Surveys: current population estimates using the AIDS Impact Model. HIV/AIDS Emergency Action Plan, Federal Republic of Nigeria 1999

5. Offiong RA, Bunza FM, Uya AO. Prevalence of HIV infection among prenatal patients in Abuja. (Abstract). Trop J Obstet Gynaecol, 2001; 18 (suppl. 1): 12

6. Ogu RN, Anya SE, Fie bai Po, John CT. The face of HIV/AIDS in Pregnancy in Port Harcourt. (Abstract). Trop JObstet Gynaecol, 2002; 19(suppl.2):31

7. Omekara SD. HIV disease among antenatal patients in Nigerian Army Reference Hospital, Kaduna - A five year review prospective study. (Abstract). TropJ Obstet Gynaecol, 2001; 18 (suppl 1): 2 .

8. Ikechebelu JI, Ikegwuonu SC, Joe-Ikechebelu NN. HIV infection and sexual behaviour among infertile women in South-eastern Nigeria. (Abstract). Trop JObstet Gynaecol, 2001; 18 (suppl 1): 9.

9. Etuk SJ, Ekure EN. Factors affecting HIV seroprevalence among pregnant women in Calabar, Nigeria. (Abstract). Trop J Obstet Gynaecol, 2001; 18 (suppl 1): 7 .

10. Wilkinson D. Mother to child transmission of HIV infection: the reality and the promise. Trop Doc, 1997; 27:220-222.

11. Working Group mother-to-child transmission of HIV. Rates of mother-to- transmission in the study population. The effectiveness of zidovudine in reducing vertical rate by about $67.0 \%$, from $25.5 \%$ to $8.3 \%$ in pregnant women between 14 and 34 weeks gestation and continuing through delivery and to the infant for 6 weeks has been shown ${ }^{10-16}$. Also the Pediatric AIDS Clinical Trial Group Protocol 250 Team has proved the success of a simple cost-effective twodose Nevirapine in the reduction of vertical transmission by about $44.0 \% \%^{17,18}$. These measures can be offered to HIV seropositive mothers in the study area. Initiation of artificial formulae instead of breastfeeding in patients who can afford it, is also worth trying in developing countries, where the advantages of artificial formulae outweigh the risks. These cost-effect interventions have been seriously advocated in developing countries ${ }^{19}$ and are worth exploring in resource poor countries; governments and other health care providers are called upon to make this a priority in the fight towards reduction in vertical transmission rate of HIV infection.

Despite these limitations, the present study serves as a base line for future studies. The study also showed that no effective intervention was put in place to control vertical transmission in the study area. Most of these mothers were not offered anti-retroviral drugs and there was no effective measure taken to prevent vertical transmission during delivery. The high maternal seropositivity with its associated high child seropositivity and poor perinatal/neonatal outcome as highlighted in this study calls for interventions that could reduce maternal morbidity and improve perinatal outcome such as anti-retroviral therapy must receive more serious attention. There are thus strong grounds to articulate effective and efficient management plan for mothers who are HIV seropositive in pregnancy, during delivery and in the postpartum period, as is the case in developed countries.

child transmission of HIV-1 in Africa, America and Europe, $J$ Acquir Immune Defic Syndr Hum Retrovirol, 1995; 8: 506-510

12. DeCock KM, Fowler MG, Mercier $\mathrm{E}$, et al. Prevention of mother-to-child HIV transmission in resource-poor countries. JAMA, 2000; 283:11751182 .

13. Connor EM, Sperling RS, Gelber R, et al. Reduction of maternat-infant transmission of human immunodeficiency virus type 1 with zidovudine treatment. $N$ EnglJMed, 1994; 331: 1173-1180.

14. Giaquinto C, Ruga E, Giacomet V, Rampon O, D'Elia R. HIV: mother to child transmission, current knowledge and ongoing studies. Int J Gynaecol Obstet, 1998; 63(suppl.1): 161-5.

15. Mercy D and Nicoll A. We should routinely offer HIV screening in pregnancy. BrJ Gynaecol Obstet, 1998; 105:249-2S1.

16. Carusi D, Learman LA, Posner SF. Human immuno-deficiency virus-test refusal in pregnancy: a challenge to voluntary testing. Obstet Gynaecol, 1998; $91: 540-5$

17. Mirochnick M, Fenton T, Gangnier P. et al. Pharmacokinetics of nevirapine in human immuno-deficiency virus type 1 -infected pregnant women and their neonates. JInfec Dis, 1998; 178:368-74.

18. Guay LA, Musoke P, Fleming T, et al. Intra-partum and neonatal single dose nevirapin compared with zidovudine for prevention of mother to child transmission of HIV $\mathrm{I}$ in Kampala, Uganda. Lancet, 1999; 354: 795-802.

19. Ibekwe PC, Ikeme AC. Routine screening for HIV infection in booked antenatal women: How justified in developing countries? Afr $J$ Repro Healih, $2001 ; 5: 7-9$. 